\author{
Available online at https://www.rjtl.org \\ Volume: 2, Issue: 1, 66-70, 2021 \\ ISSN: 2708-3632 \\ DOI: https://doi.org/10.46590/rjtl.2021.020101
}

\title{
Sustainable Finishes for Healthcare Apparels
}

\author{
J.M. Subashini ${ }^{1}{ }^{*}$, Dr. G. Ramakrishnan ${ }^{2}$ \\ ${ }^{1} \mathrm{M}$. Tech Scholar, ${ }^{2}$ Professor, \\ Department of Fashion Technology, Kumaraguru College of Technology, Coimbatore.
}

\section{Paper History}

Received: December 2020

Accepted: January 2021

Published: February 2021

Corresponding Author

J.M. Subashini

subashini.19mat@kct.ac.in

\begin{abstract}
The conventional textile finishing process used to consume a high amount of water, chemical and energy source which leads to more hazardous waste material and polluting the environment. To replace these conventional methods, working towards sustainable manufacturing is more consideration for the need of an hour. In the field of medical textile, the finishes used for manufacturing the health care apparels should enhance the desired properties that the patient and the health care personals need. For this purpose, the advanced and eco-friendly finishing process has been developed. Thus in this paper, the sustainable and eco-friendly finishing process used in the field of medical textile has been discussed in detail.
\end{abstract}

Keywords: Eco-friendly textile, medical textile, microencapsulation, nanotechnology, plasma technology, sustainable finishes.

Citation: J.M. Subashini, Dr.G. Ramakrishnan, Sustainable Finishes for Healthcare Apparels. Research Journal of Textile and Leather, 2(1), 66-70, 2021.

\section{INTRODUCTION}

Sustainable finishes refer to sustainable textile processing methods that are capable to deliver not only eco-friendly finished products but also creel our surrounding atmosphere and therefore the environment without polluting the air and water respectively, due to emission of harmful gases and effluent water discharges[1]. The word sustainability is defined as meeting the requirements of the present without compromising the ability of future generation to fulfil their own needs. Environmental consideration is now becoming vital factors during the choice of commodity including textile everywhere the world. Healthcare apparels such as uniforms, scrubs, lab coats, isolation gowns which are worn by the healthcare workers and the patients should provide barrier protection without infecting from the micro-organisms or pathogens that can cause infections or illnesses. The important in creating awareness about sustainability should be preached, as in recent times, these textile materials are worn for a longer time by the healthcare workers, which should not cause damage to their skin. Some of the new technology used in the finishing of healthcare apparels includes Plasma treatment, Nanotechnology and Microencapsulation method. The anti-microbial properties using eco-friendly solutions can be incorporated to the healthcare apparels using these finishing technologies which provides a better barrier against micro-organisms.

\section{AN ECO-FRIENDLY ATTITUDE}

Medical textile over the past decade has registered $4 \%$ of their annual growth. In recent research, it is reported that the medical textile sector is expected to have an annual growth rate of $3,87 \%$ in the next five years. Based on the figure, this sector's growth will be higher than the GDP growth of leading economies such as the U.S and Europe. There will be greater demand for medical and hygiene textile with the ageing population in the U.S, Europe and Japan and an increasing population of young people in developing countries such as India. To date, the medical textile sector has been focused its consideration on functionality, quality and standard complain, so that the next stage is to develop cost-effective "greener" processes and medical products to support the next generation health care industry[2].

\subsection{Burlington Medical Barrier Fabric - Reusable}

Burlington manufactures develops their range of Maxima ${ }^{\circledR}$ and XALTTM barrier fabrics for the healthcare workers using state of the art polyester yarns, constructions and finishes according to the Association for the Advancement of Medical Instrumentation ${ }^{\circledR}$ (AAMI) certification and EN13795 European standards. Burlington's medical fabric durability makes the garment to be extended beyond its original use. For example, the material is certified for A level 2 protection are often tested through 75 


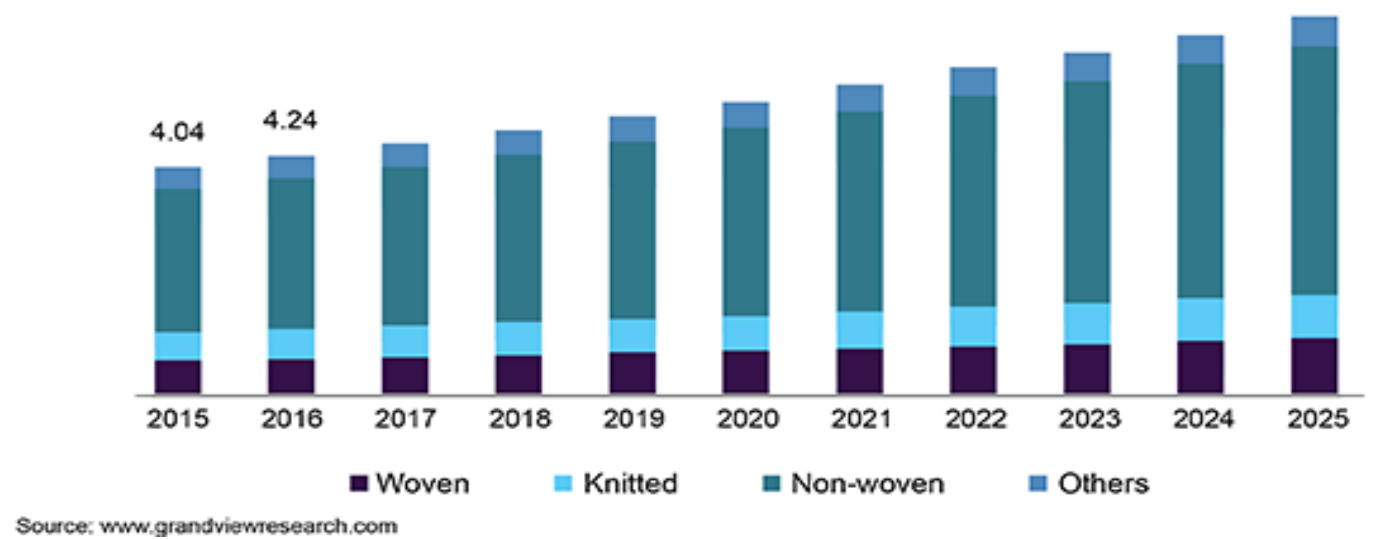

Figure 1. Analysis of U.S Medical Textile Market report

launderings but at the top of that point, it can still meet certification for level 1 protection, extending its cycle.

\subsection{SUSTAINABLE FINISHES}

Fabric finishing process has a very large impact on the environment because of using large volumes of water, significant amounts of various types of chemicals, and a lot of energy. The important issue was finishing consumption need to deal with are water discharge and its chemical load, energy consumption, air and water emission, waste, odours and noise.

To avoid large emission of water and chemical load and to reduce the consumption of energy and water and to avoid waste production, new chemicals were developed that can be reusable, water-free, biobased, or biodegradable. Current changes in the regulation of the European Union (EU) have led to the limitation or even prohibition of the use of hazardous substance during the finishing of textiles. These changes create pressure on the apparel value chain to meet the terms of fast-changing legislation [3].

\subsection{Waste Minimization in Fabric Finishing}

In general, minimization of waste can be achieved by the following limitation:

- Limitation of use of water

- Reduction of chemicals

- Minimizing the emission of toxic substances

For this reason, a decent choice of chemicals is required. By substituting hazardous substance, using bio-based, biodegradable, or reusable material, and finally looking into new technologies that use zero percent water [3].

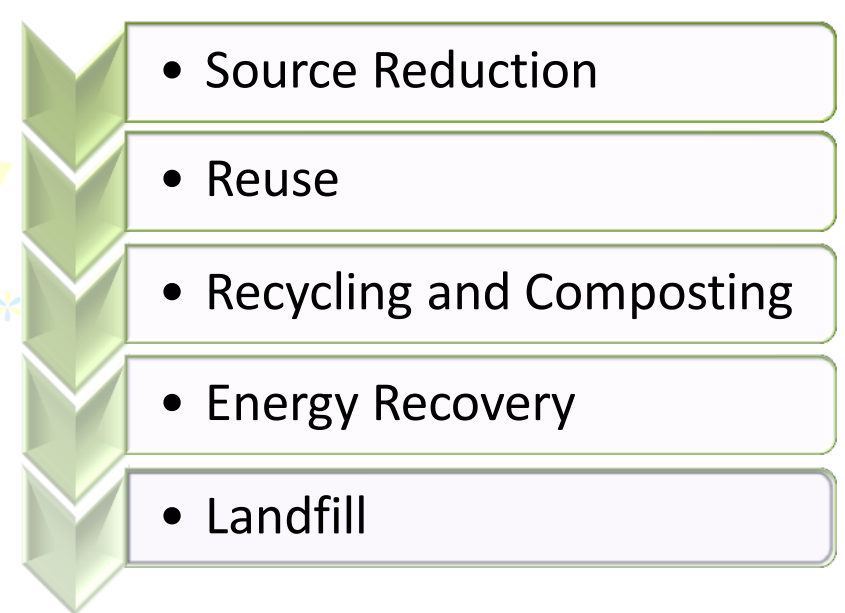

Figure 2. Represent the flow of approach to waste minimization

\subsection{Use of Bio-Based or Biodegradable Finishes}

Due to increasing consumer awareness, the impact of legislation (e.g., REACH), and the work of environmental organizations, there is a tendency towards bio, natural, and environmentally friendly products (e.g., Greenpeace). Material consisting of $\mathrm{CO}_{2}$ neutral renewable resources is being developed because of the depletion of fossil fuels and the impact of $\mathrm{CO}_{2}$ emission on the global environment. Bio-based polymers are obtained via extraction, synthesis from renewable monomers, or microbiological synthesis. Therefore, the development of biodegradable finishing and impregnation formulation is the much-needed one to decrease the environmental impact of such textile. 
This is still a challenge and required the elaboration of novel formulation.

\section{ENVIRONMENTALLY FRIENDLY ANTI- BACTERIAL FABRIC FINISHES}

Silver or quaternary ammonia-based products are mostly used, anti-bacterial finishing agent. The significant use of antimicrobial has led to the development of eco-friendly technologies for antimicrobial use. In antibacterial finishing, the application of chitosan has been widely observed. Chitosan is obtained by the de-acetylation of chitin, which is found in invertebrate exoskeletons and fungi. In chitosan, the broad spectrum anti-bacterial activity is assigned to the ammonia group in acidic conditions. Tannic acids are polyphenols which occur naturally and are found in various plants. Cotton fabric was finished with tannic acid, and antibacterial activity was evaluated and found good. Thymol and carvacrol are phenolic compounds predominantly found in an essential oil such as oregano oil and thyme. It has been reported that both compounds have antimicrobial activity and a synergistic effect. Monolaurin (mono-ester of glycerol and lauric acid) in coconut oil is found to have antibacterial and antiviral effects in vitro method. Salicylic is derived from the willow tree's bark extract.

\section{SUSTAINABLE TECHNOLOGY ADOPTION IN FINISHING HEALTH CARE APPARELS}

There are many innovative physical and engineering technologies, like laser, gas plasma, supercritical fluid extraction and microwave technology are getting used to improve healthcare textiles. The performance and functionality of biomedical products can be improved by using such advanced techniques. One such application of plasma finishing technique enables the plasma as a channel to coat durable antimicrobials. In a study, anti-microbial such as silver and ammonium chloride agent was deposited using different forms of plasma, such as atmospheric plasma.

An important requirement for surgical gowns and drapes is body fluid repulsion. Eco-friendly plasma at certain room temperature has been capably used to develop cotton surgical gowns with water repellent property by grafting chemicals like hepta-decafluorodecyl acrylate which minimizing water and other application fluids. To increase the surgeons' comfort, and to impart superhydrophobicity and fluid repellence, plasma bombardment has been successfully applied by creating minute pore in spun bond non-woven made of polypropylene fibres, while wearing such gowns for a long time during complex surgical processes. More than all, continuous and cost-effective atmospheric plasma was used to make synthetic polypropylene as cottonlike fabric [2].

\subsection{Plasma Treatment}

Plasma technology has been made to enhance the fibre surface properties without being affecting the desirable properties already present in it. It offers more environmental advantages. This results in enhancing the use of plasma technology on synthetic fibres like nylon, polyethene terephthalate, polypropylene, etc. In a research, it is found that the plasma treatment will not alter the tensile properties, weight and thickness of surgical gown. Thus this type of finishing technique for the development of surgical gown makes the material to be liquid proof and protect the bloodborne infectious microbes from penetrating through the fabric. Plasma treatment is the method used for grafting of textile fibre with another polymer to enhance desirable properties needed. Polyethene terephthalate would be wideopen to use oxygen plasma glow discharge for the formation of peroxide in their surface. In the plasma treatment, the graft polymerization takes place with the presence of oxygen to generate hydrophilic surface in hydrophobic fibres such as polyester or polypropylene [4].

\subsubsection{Sustainable Approach of Plasma Finish in Textile}

The plasma treatment helps to reduce the amount of water and chemicals used, compared to the conventional processing along with better exhaustion of chemicals from the bath. Plasma treatment has the best advantage of consuming less energy over the conventional method. The principal role of plasma surface treatment is to improve the properties of textile materials such as wettability, adhesion, biocompatibility, protection and anti-wear [5].

The textile and clothing industry is facing some of the big challenges today mainly due to globalization. The growing environment and energy-saving concerns will lead to the steady replacement of conventional wet processing technique [6]. Plasma technology has a strong potential to provide an effective way to achieve new horizons in the field of textile technology.

\subsection{Microencapsulation Method}

Microencapsulation is one of the most unique and an innovative method of providing functional finishes to the textile material. Microencapsulation is a technique which contains micro-packing of the particle to get deposit as a thin polymeric coating of small particles of solid or liquid on to the surface of the fabric. This process is beneficial to conventional 
textile processing in terms of energy-saving, economy, eco-friendly and controlled release of substances. The anti-bacterial agents exist in in colloidal suspension present with the amorphous zone of the polymeric binder so that within the polymeric matrix the reservoir of the agent is present in the solid or solution form.

Bacterial and virus often cause microbiological decay of fabric which in turn affect the loss of many useful properties of the fabric. This issue can be prevented by applying the anti-microbial with the help of micro-encapsulation using the release mechanism. This finish is essentially used for textile for medical and technical uses [8].

\subsubsection{Sustainable Approach of Micro- Encapsulation Finish}

The ideal feature for the textile application using the micro-encapsulation technique is that this technique is easy to apply, will not affect the existing textile properties and can survive up to 25-30 wash cycle than the conventional process. This type of finish with the anti-microbial components does no harm to the environment and provides a more effective and durable finish and these products are also biodegradable.

Compared to other conventional finishes microencapsulation finish may have long term goals. The needful for a healthier and more protective lifestyle will continue to create a market for textile, which can promote well-being and relate with the consumer endorsing comfort can be made possible through active delivery from the micro-encapsulation finish.

\subsection{Nanotechnology}

Nanotechnology is defined as the technology which deals with material which is smaller than 100 nanometers. It is one of the most innovative and rapidly emerging technologies in the field of textile finish in $21^{\mathrm{st}}$ century. In recent years, there are much research conducted on noble metal nanoparticles due to their unique electronic, mechanical, magnetic, chemical and optical properties. Materials in the range of $1 \mathrm{~nm}-100 \mathrm{~nm}$ are mainly focused on this type as it has much interest because in this range the numbers of newer properties become effective.

Nanotechnology significantly focuses on handling, assembling and controlling of nan scale structures to integrate into large material structure and components. The anti-microbial finish of textile material is the most widely used example for nanotechnology. Finishing of textiles with nanoparticle as anti-bacterial compounds have been an attempt in recent years and we could say that it is the future technology which increases the effectiveness of functional finish in textile materials. Due to an increase in awareness about health and hygiene, people are highly concern and want their clothing to be highly protective [9].

\subsubsection{Sustainable Approach of Nano Finish in Textile}

The conventional method of the finishing process with the textile chemicals can provide the functional properties requires, but at the same time, they cause pollutant and affect the nature of the fibres used which results in lack of comfort. But the use of nanotechnology provides high durability for fabric with the sustainable approach without affecting the breathability or hand feel of the fabric.

The high durability of the fabric is of its smaller size particle and high surface area. Though the cost of the finish is higher compared to other types of the textile finishing process, it has very low energy consumption and provides a clean and sustainable finishing process. This approach leads nextgeneration inventions in the field of nanotechnology in textile processing, where the required effect and the properties can be incorporated into the fabric [10].
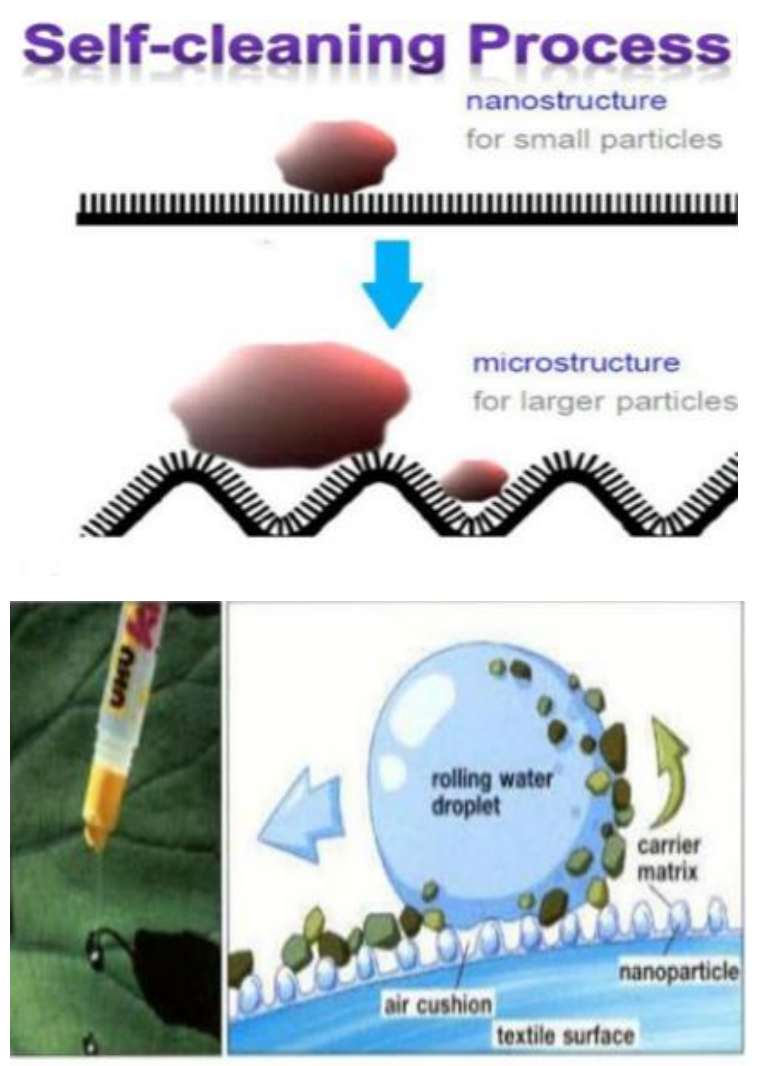

The self-cleaning surface by lotues effect.

Figure 3. Self-cleaning process of nanoparticles coated in the fabric 


\section{FUTURE TRENDS IN SUSTAINABLE FINISHES}

In general term, sustainable fabric finishing is to use fewer chemicals and less water. However, it is not clear since it demands the replacement of often cheap as well as well-known methods and products. Such a change often imparts, mainly at the beginning of the change-over, process instabilities, quality differences and the like. In future, the use of chemicals in finishing of fabric and apparels will be defined by various players like ECHA/REACH, environmental organizations and brands [11].

The effect of changes made in fabric finishing by REACH is large. The concept of chemical leasing, a novel business model of sustainable chemical management, is another future development in which the producer's liability rises as the producer no longer only sells the chemical products but also remains the owner of the product. As like, the producer supports in textile processing is responsible for the waste management of the chemical used in the process. This model is proposed to endorse more successful chemical management.

\section{CONCLUSION}

Medical textile in the most important field of technical textiles. This sector should now emphasize sustainability in developing process and products which are cost-effective. It should be understood that in long term benefits such as a smaller carbon footprint, superior overall performance and user acceptance will balance the cost accompanying with being "greener product". More sustainable and more environmentally friendly medical textiles will lead to developing economies which is a challenge for the industrial fabric industry. Thus textile industries are now being able to develop one-stop sustainable solution along with the textile value chain from pretreatment, from dyeing to finishing. By embracing eco-friendly finished, the entire clothing supply chain will add value. Manufacturers benefit from using minimal water and reducing energy consumption, while the customer will not need to wash their clothes at higher temperatures.

\section{REFERENCES}

[1] https://www.scribd.com/document/239273 978/Eco-Textile-Processing

[2] Green medical textiles: the next phase by Seshadri Ramkumar, August 21st, 2015 / By: IFAI / Feature

[3] Blackburn, Richard, ed. Sustainable apparel: Production, processing and recycling. Woodhead Publishing, 2015
[4] Khatri, Awais \& White, Max. (2015). Sustainable Dyeing Technologies. 10.1016/B978-1-78242-339-3.00005-4

[5] Shishoo, Roshan. (2007). Plasma technologies for textiles

[6] Raichurkar, Pramod. (2011). Study The Effect Of Material To Liquor Ratio In Yarn Dyeing

[7] Periyasamy, Aravin Prince, and M. Tech. "Eco-Friendly in Textile Wet Processing." (2012).

[8] Shrimali, K., \& Dedhia, E. (2015). Microencapsulation for Textile Finishing. IOSR Journal of Polymer and Textile Engineering, 2(2), 1-4.

[9] Al-Dabbagh, B. A. L. Q. E. E. S., And H. A. N. A. Al-Shimari. "Preparation Of Nano-Silver Particles By Chemical Method For Anti-Bacteria's Applications." Int. J. Nanotechnol. Appl 3.5 (2013): 21-26.

[10] https://www.scribd.com/presentation/3319 12568/Application-of-Nano-Technologyin-Textile-Finishing

[11] https://www.fibre2fashion.com/industryarticle/5838/value-added-textiles-technicalcommercial-ecological-finishes

[12] Weydts, D., De Smet, D., \& Vanneste, M. (2015). Processes for reducing the environmental impact of fabric finishing. In Sustainable Apparel (pp. 35-48). Woodhead Publishing.

[13] https://www.fibre2fashion.com/industryarticle/5838/value-added-textiles-technicalcommercial-ecological-finishes. 